\title{
ON THE PTOLEMY CONSTANT OF SOME CONCRETE BANACH SPACES
}

\begin{abstract}
ZHAN-FEI ZUO
Abstract. In this paper, we firstly consider the relations involving the Ptolemy constant of the norms $\|.\|_{\psi}$ and $\|.\|_{\phi}$, where the convex functions and $\psi$ and $\phi$ are comparable. Secondly, we determine this constant when norm is a mean of two norms. Finally, the constant was calculated for some concrete Banach spaces.
\end{abstract}

Mathematics subject classification (2010): Primary 46B20, Secondary 46B25.

Keywords and phrases: The Ptolemy constant, Absolute normalized norm, Convex function.

\section{REFERENCES}

[1] J. Alonso And P. Martin, A counterexample for a conjecture of G. Zbăganu about the NeumannJordan constant, Rev. Roum. Math. Pures Appl. 51, (2006), 135-141.

[2] F. Bonsall and J. Duncan, Numerical Ranges II., London Mathematical Society Lecture Notes Series, 10, Cambridge Univ. Press, New York, 1973.

[3] J. GAO AND K. S. LAU, On two classes Banach spaces with uniform normal structure, Studia Math. 99 (1991), 41-56.

[4] T. IKEDA AND M. KATO, Notes on von Neumann-Jordan and James constants for absolute norms on $\mathbb{R}^{2}$, Mediterr. J. Math. 11 (2014), 633-642.

[5] A. Jiménez-Melado, E. Llorens-Fuster and S. SAejung, The von Newman-Jordan constant, weak orthogonality and normal structure in Banach spaces, Proc. Am. Math. Soc. 134 (2006), 355364.

[6] N. Kalton And I. Verbitsky, Nonlinear equations and weighted norm inequalities, Trans. Amer. Math. Soc. 351 (1999), 3441-3497.

[7] M. Kato And Y. TaKahashi, On the von Neumann-Jordan constant for Banach spaces, Proc. Amer. Math. Soc. 125 (1997), 1055-1062.

[8] M. Kato AND L. MaligRAnda, On James and von Neumann-Jordan constants of Lorentz sequence spaces, J. Math. Anal. Appl. 258 (2001), 457-465.

[9] M. Kato, L. MaligRAnda AND Y. TAKAhashi, On James and Jordan-von Neumann constants and normal structure coefficient of Banach spaces, Studia Math. 144 (2001), 275-295.

[10] E. Llorens-Fuster, E. Mazcuñán-NaVArro And S. Reich, The Ptolemy and Zbăganu constants of normed spaces, Nonlinear Analysis 72 (2010), 3984-3993.

[11] L. Maligranda And L. E. Persson, Generalized duality of some Banach function spaces, Indag. Math. 51 (1989), 323-338.

[12] K. Mitani And K. Saito, The James constant of absolute norms on $\mathbb{R}^{2}$, J. Nonlinear Convex Anal. 4 (2003), 399-410.

[13] H. Mizuguchi And K. Saito, Some geometric constants of absolute normalized norms on $\mathbb{R}^{2}$, Ann. Funct. Anal. 2 (2011), 22-33.

[14] H. Mizuguchi AND K. Saito, On the upper bound of some geometric constants of absolute normalized norms on $\mathbb{R}^{2}$, Mediterr. J. Math. 13 (2016), 309-322.

[15] H. L. Nikolova And L. E. Persson, Some properties of $X^{p}$ spaces, in: J. Musielak, H. Hudzik, R. Urbanski (eds.), Function spaces, Teubner-Texte zur Matematik 120 (1991), 174-185.

[16] L. Persson (Eds), Some elementary inequalities in connection with $X^{p}$ spaces, Constructive theory of functions, Publishing House of the Bulgarian Academy of Sciences, (1988), 367-376.

[17] Y. PINCHOVER, Maximum and anti-maximum principles and eigenfunctions estimates via perturbation theory of positive solutions of elliptic equations, Math. Ann. 314 (1999), 555-590. 
[18] Y. Pinchover, S. Reich And I. Shafrir, The Ptolemy constant of a normed space, Amer. Math. Monthly. 108 (2001), 475-476.

[19] S. SAEJUnG, On James and von Neumann-Jordan constants and sufficient conditions for the fixed point property, J. Math. Anal. Appl. 323 (2006), 1018-1024.

[20] K. SAito, M. KATO AND Y. TAKAhAShi, Von Neumann-Jordan constant of absolute normalized norms on $C^{2}$, J. Math. Anal. Appl. 244 (2000), 515-532.

[21] R. TANAKA, Tingley's problem on symmetric absolute normalized norms on $R^{2}$, Acta Math. Sin. 30 (2014), 1324-1340.

[22] Z. ZUO AND Y. CUI, Some modulus and normal structure in Banach space, Journal of Inequalities and Applications 2009 (2009), Article ID 676373.

[23] Z. ZUO, The Ptolemy constant of absolute normalized norms on $R^{2}$, Journal of Inequalities and Applications 2012 (2012), 107.

[24] Z. Zuo, A reconsideration on the Ptolemy Constant of absolute normalized norms, Acta Mathematica Sinica (Chinese Series) 58 (2015), 337-344.

[25] Z. ZUO AND C. TANG, Jordan-von Neumann type constant and fixed points for multivalued nonexpansive mappings, Journal of Mathematical Inequalities. 10 (2016), 649-657. 